\title{
Personalised system of instruction: The ODL way
}

\author{
Prakash Arumugam \\ Wawasan Open University, Malaysia
}

\begin{abstract}
All academic institutions subscribe to systems and methods that are deemed appropriate for the delivery of courses or programmes to the general masses. Some emphasise on physical delivery as in conventional institutions. Some employ a blended approach as in distance learning institutions. In modern times, we see conventional institutions making use of a mixture of conventional face-to-face and modern e-learning approaches in delivering programmes.

In the 1960s, an experimental method of instruction was introduced by Fred Keller. It was aptly named Keller's Personalised System of Instruction (PSI) and it stayed on the educational radar right through the 70s and 80s. This non-traditional method of instruction, which dominated colleges and universities, was regarded as superior to conventional methods. It was originally used in a conventional education setting or face-to-face teaching environment. Unfortunately, its popularity slowly waned in subsequent decades. The original PSI method contained five defining features and these are applied, inadvertently or otherwise, by distance education institutions in their delivery of courses.
\end{abstract}

The purpose of this study is to examine the exploitation of PSI in the delivery of courses at Wawasan Open University (WOU). To facilitate the investigation, the elementary level Microeconomics course was selected. The study reveals that PSI principles, in general, are applied in WOU with twists that fit into institutional and cultural norms, bearing in mind the attention the university pays to quality.

\section{Introduction}

Wawasan Open University (WOU) is the second private university dedicated to open and distance learning in Malaysia. The university is in the middle of its sixth year of operation, having concluded 11 semesters. There are four schools in the university: the School of Business and Administration, the School of Science and Technology, the School of Foundation and Liberal Studies and the School of Education, Languages and Communication. Together, these schools offer programmes ranging from foundation right up to postgraduate levels. To assist in the delivery of the programmes, the university has established regional learning centres called regional offices in six towns or cities. Tutorials are conducted in these centres using local human resources. 
The School of Business and Administration (SBA) offers eight undergraduate degree programmes and several graduate diploma programmes. The school also offers three postgraduate programmes: the Commonwealth Executive Master of Business Administration (CEMBA), the Commonwealth Executive Master of Public Administration (CEMPA) and the Postgraduate Diploma in Business Administration. The profile of students in all the programmes is similar as is usually the case in a distance learning institution. This investigation focuses on the use of the Personalised System of Instruction (PSI) in the elementary Microeconomics course, which is a basic major for all undergraduate business students.

All courses (the term "subject" is used in some universities) are delivered to students via the distance learning mode. Tutorials are held in regional learning centres with an appointed tutor for each class. There are a maximum of 30 students to a tutor for the undergraduate programmes and 25 to a tutor in the postgraduate classes. Occasionally, tutorials are carried out using video conferencing, web conferencing (WizIQ) or even Skype. This is necessary when the number of students in a particular course is small or when the course coordinator (this is the terminology used for fulltime academic staff in WOU) decides to conduct additional tutorials.

\section{Literature review}

The study of a more personalised or individualised system of instruction goes way back to the 60s. There was an urgent need to develop a different and more contemporary method of teaching and learning. Technically born in Brazil, the Personalised System of Instruction (PSI) was brought to the United States and experimented with by Fred Keller and J. G. Sherman (Keller, 1968).

Most of the early studies on PSI were done with the conventional educational institution in mind. After all, it was in these institutions that this method first flourished. Keller (1968) first thought of the need to develop a system that would apply reinforcement thinking to the teaching process. This was necessary as the conventional teaching environment was deemed inadequate in shaping young minds (Keller, 1968).

The seminal paper "Goodbye Teacher..." by Keller (1968) explained in detail how PSI was administered in a general psychology class at the Arizona State University. The core of this unique method of "teaching" as provided in Keller's work comprised self-pacing, mastery criterion, the use of lectures as a motivational tool, emphasis on written works and the use of proctors. Of the five, the one oft researched is the mastery criterion. Abbot and Falstrom (1977) studied a basic Statistics class by comparing a typical lecture version and a Keller version of delivery. They concluded that the mastery criterion was not a required element in order to achieve the same level of performance in a traditional class as in a Keller course.

Dubin and Taveggia (1968) analysed 74 empirical studies on different teaching methods and found that there are no significant differences in any of the methods used on student performance. In summarising the results of 14 separate studies, Taveggia (1976) concluded 
that "when evaluated by average student performance on course content examinations, PSI has proven superior to the conventional methods with which it has experimentally been compared to." This gave credence to alternative methods of learning as viable options since student controlled learning methods are just as effective as instructor controlled ones. The popularity of PSI was more evident in higher education courses in the 70s (Sherman, 1992).

Unfortunately, the fire died down after a couple of decades with waning interest in PSI. Sherman (1992) listed three main reasons for this decline: a reluctance to use PSI, lack of information dissemination and defining PSI. Basically, instructors feared losing control of the delivery of education, more so with the heavy reliance on proctors. Instructors, who have the greatest subject matter expertise, and students are gravely distanced (Gallup \& Alan, 2002).

The recent revival is seen in an attempt to utilise PSI in a distance learning environment. The wide use of self-instructional materials in a distance learning environment opens up an opportunity to apply PSI in this form of delivery (Grant \& Spencer, 2003). Course content is usually presented in a written study guide or course material, with questions to assist students in achieving the learning outcomes.

\section{Keller's Personalised System of Instruction}

Keller's PSI was originally designed to assist students in Brazil, at the newly set up University of Brasilia, to learn resource materials without the need to have an instructor or lecturer present. When Keller came back to the United States, he brought his PSI programme along to try it out with the locals (students at the Arizona State University, specifically). In the initial stages, the method was more popular among professors in psychology and it eventually spread to other areas of study. Keller (1968) outlined five basic components that he deemed essential for a PSI class:

1. Go-at-your-pace feature (self-pacing).

2. Unit-perfection requirement (mastery of course material).

3. Use of lectures and demonstrations as vehicles for motivation.

4. Stress upon the written word.

5. The use of proctors. 
The self-pacing feature of PSI courses allows students to move through the course material at their own pace. Thus, they can spend less time on material they understand and more time on areas they find difficult. In the initial PSI courses developed by Keller, students were not constrained by the traditional semester barriers. Rather, they could continue to work on a given course until they passed all of the unit tests. This is something that traditionally bound institutions can ill-afford.

In a standard PSI course, the course material is broken down into small units of study; for example, chapters or sections within a chapter. In his original notes, with reference to a course in General Psychology, the course was divided into 30 units of content (Keller, 1968). The units will be in a numerical order and mastery of each unit is reflected in the passing of a "readiness" test. Only when a student has successfully demonstrated comprehension of a unit can he move on to the next. Failure to pass a test is not held against students as "it is better to get too much testing than not enough..." (Keller, 1968). Students can always restudy the information and retake the unit test as many times as it takes for them to demonstrate mastery of the material. Course credits are awarded when students pass the test but as expressed earlier, there will be no penalty imposed for failing. The intent behind this is to reinforce test-taking attempts and mastering those tests while not punishing incorrect responses or failed attempts at mastery. One unusual aspect of PSI is that students are given the opportunity to defend an incorrect answer (Keller, 1968), which is rare in a conventional setting.

Keller (1968) saw instructors as facilitators of learning rather than the person who actually imparts the knowledge. Classroom meetings are typically used to help clarify material and motivate students to be engaged learners. Whether motivation did improve is a different matter altogether. Born and Herbert (1971) reported that attendance in these lectures gradually declined as there were no rewards for attendance. This has been cited as one of the reasons why PSI met an early demise (Kulik et al., 1974). Most of the learning of the material takes place outside of the classroom through students' active reading of the textbook and supplementary materials.

The primary means of communication between student and instructor is through written words. Study guides in the form of chapters from textbooks are given to the students with a couple of sets of programmed versions of similar materials. Accompanying all this is a list of study questions (about 30 in number). Students are asked to look up the answers to the study questions while reading the text. This will help them prepare for the readiness test. Proctors (teaching assistants) will also provide written feedback on the students' answers to the test so that they will learn and avoid mistakes in future units. Interestingly, verbal communication between students and peers (proctors) are highly encouraged in demonstrating mastery of course material (Sherman, 1992).

The teaching staff of the original PSI model consisted of proctors, assistants and instructors. Proctors were usually undergraduate students who had demonstrated mastery of the subject matter and were chosen based on their maturity of judgement. Some researchers used alternative names like mentors, peer-reviewers or tutors to reflect the actual role played by proctors. 
Sherman (1977) referred to students who had enrolled in a course and passed a given unit as internal proctors. On the other hand, external proctors were students who had taken the course previously (and passed) and were hired or given course credit for serving as proctors (Sherman, 1992). The proctors provided individualized feedback to PSI students about their unit test performance and often provided individualized tutoring in areas where the student was weak.

\section{PSI in WOU}

Does WOU practice Keller's PSI? A quick answer would be "yes". Do we follow the original model as proposed by Keller? We cannot, as it does not seem to be entirely suitable for the institutional norms of the university. This section examines the existence of PSI in WOU. The explanation below pertains to the Microeconomics course, which is a basic major course in all the undergraduate programmes offered by the School of Business and Administration. At this point, a reminder is in order as not all courses in the university employ the same practices as the one outlined. Different academic staff would have different ways of delivering a course.

Pacing is a fundamental feature of any distance learning environment as the very nature of our students does not allow rigidity to exist. A study schedule that outlines the topics to be completed and the activities that need to be attempted within a certain time frame is given to the students in the Microeconomics course. This fulfils the purpose of pacing the students' study. Most of the activities are already in the course material or the recommended textbook. Students are also asked to attempt quizzes in the learning management system (LMS) used by WOU. There are a total of seven quizzes pertaining to each unit in the course material (the more advanced units warrant more quizzes). The quizzes are designed to give immediate feedback upon completion. Students can attempt the quizzes as many times as they want to. Students are asked to seek an explanation for a particular quiz or question from the tutor in charge of their respective classes either via the LMS or during tutorials. In this manner, the interaction between learner and tutor improves. However, no grades are awarded for any of the activities or quizzes. These are merely used as a progressive learning tool rather than as an assessment.

The standard design of course material in WOU consists of two major components: the course material and a course guide. The guide reminds students of the intricacies of studying in a distance learning environment. The learning outcomes and objectives of each course are outlined in the guide together with the assessment methods and prescribed textbook. The course material, however, is the full text of the curriculum developed as a standalone (in some cases wrap-around or adapted) self-contained learning material. The materials are divided into five units and each unit is further divided into three to five sub-units. Each sub-unit ends with self-tests to gauge students' understanding. Each unit ends with activities or self-tests to measure students' comprehension of the unit. A set of suggested answers are provided at the end of each unit for students to gauge their comprehension level. 
There are no "readiness" tests administered in WOU where students (all of whom are working adults) are barred from moving on if they have not completed a unit as they are not practical in this environment. Although students study at their own pace, they are still controlled by a typical semester system in which they are expected to finish the course at the end of the semester. Failure to do so results in re-enrolment in subsequent semesters until the student completes the course and the programme. The activities and self-tests in the units play the role of "readiness" tests with the distinction being that the student evaluates and grades himself by playing the role of a proctor. In this way, the student has better control over his own direction.

There are no lectures, as such, in WOU and in most other distance learning institutions. Tutorials are conducted throughout the semester. Each tutorial lasts two hours and there are five of them in a semester. This fits in well with the number of units that a course has, which is five. The tutorials serve to assist students in learning the units of the course through a series of activities. Feedback on graded assignments is provided to students as part of the learning process. Future assignments are also discussed to ensure student comprehension. Apart from all that, discussions on the concepts and principles that need to be learnt to fulfil the requirements of the unit (and course) are also covered. It may seem that two hours are not sufficient but tutorials of this duration have been successfully conducted in WOU as well as in several other distance learning institutions. It all boils down to the efficient use of time and resources. Although this is not what Keller envisioned, tutorials tend to improve student motivation (Williams \& Williams, 2011) as the rare face-to-face sessions may boost overall confidence. As in Keller's plan, tutorials at WOU are not compulsory, although they are used as a "source for critical information" (Keller, 1968).

WOU uses tutors as proctors to lead its tutorials and serve as the frontline "soldiers" who enhance student-instructor communication. Wittig (1974) states that tutors can increase a learner's motivation level by adding a personal touch to unmotivated students. They also grade students' assignments, which are called tutor-marked assignments (TMA). Tutors are also expected to provide written feedback on students' assignments. These graded assignments and feedback are later monitored by the academic staff (instructors) at the main campus. This is to ensure quality in the grading as well as in the feedback. This is one of the unique features of WOU, where constant attention to quality assurance is given to every facet of the course and programme.

\section{Comparison of PSI and WOU-PSI}

\section{Go at your pace feature}

Self-pacing is done in a more traditional manner in WOU. The university cannot afford to allow students the freedom to take their own sweet time to complete a course of study. There are graduation implications for a student. The only consolation students get in WOU is that they are allowed to repeat a course as often as they want until they are satisfied. There is no maximum time limit to WOU programmes and one can be enrolled in a programme forever, literally. 
Until the end of 2012, a typical Microeconomics class would have three TMAs for the students to complete. The deadline of each TMA is carefully placed in the $6^{\text {th }}, 10^{\text {th }}$ and $15^{\text {th }}$ week of a semester respectively. This gives students ample time to complete each TMA for submission. Tutorials are, however, held in the $1^{\text {st }}, 5^{\text {th }}, 9^{\text {th }}, 13^{\text {th }}$ and $18^{\text {th }}$ week of a semester. This sort of planning provides students with the opportunity to attend the tutorials before submitting their respective TMAs. Although this is also a form of pacing, it is done by the university for the benefit of the students; therefore it does not exactly fit the definition of self-pacing. WOU is aware that self-pacing needs the sort of discipline that is not easy to come by.

Research has shown that successful distance learners have an internal locus of control and are effective time mangers (Wang \& Newlin, 2000). However, most students may not be able to effectively self-pace their studies. As pointed out by Belland, Taylor, Canelos, Dwyer and Baker (1985), allowing self-pacing results in poorer performance among students and as such, a moderate level of external pacing is necessary.

\section{Unit-perfection requirement}

Just like Keller's PSI, WOU courses are also divided into smaller chunks for easy manageability on the part of the students. The major difference would be that one does not need to pass a unit before moving on to the next. The units serve as part of the progressive learning process of a student. Although there are assessments and self-tests, these do not meet the mastery of the unit criterion.

In Keller's model, failure to obtain the minimum criterion needed to complete a unit would mean that a student retakes the unit as many times as necessary to demonstrate mastery. This is essential in allowing them to move forward. This was possible as the first cohort of students tested with this new method were not bound by the traditional academic system.

Interestingly, this is a component that WOU can be proud of to a certain extent. Students are expected to obtain a minimum pass in the course assessment to be deemed to have completed the course. However, students may also repeat or re-enrol in a course to improve their grade. At WOU, one can retake a course as many times as one wants until one is satisfied with the results. In a way, this also improves the mastery of the course. Whether a student appreciates this or not is a different matter altogether and will not be discussed here.

\section{Use of lectures as a vehicle for motivation}

Due the nature and culture of educational institutions in Asian countries (and perhaps the world), students are more inclined to the concept of being taught rather than the concept of self-learning. Basically, students want to be taught and do not want to be independent learners. If this holds true, then lectures as a vehicle for motivation would not work in Asian universities. WOU students, like their other Asian counterparts, strongly support the idea 
of having lectures and tutorials. The current two hours allocated for tutorials are deemed insufficient by students. In a distance learning institution where students and instructors are separated, these tutorials add that little bit of human interaction that is vital for wholesome mental growth (Wittig, 1974). If that is the case, then the original PSI notion that critical information may have to be sourced independently by students may not be feasible with Malaysian students. Studies would need to be conducted to test this premise as there are hardly any at the moment on Malaysian students.

\section{Stress upon the written word}

Obviously, written communication is the primary means of communication in any educational setting. In a distance learning institution where there are few face-to-face meetings, resources need to be provided to ease the burden of students looking for reading materials. As mentioned earlier, self-directed learning materials are provided by WOU for all its students regardless of the level of study. Feedback is also given to students when their TMAs are graded. This feedback is essential to boost the confidence and motivation level of students. Seemingly, the written feedback plays a similar role to using lectures as a motivational tool. Verbal feedback is also equally important as many students are open and receptive to a more personal relation with the learner's aid (Burnett, 2002) than just reading comments written on a piece of paper.

\section{Use of proctors}

Proctors play the role of assistants who grade and decide whether a student has enough mastery of a unit to allow the student to move forward. The proctors' grades and judgement will "ordinarily be law" (Keller, 1968). In cases of doubt, the proctors may refer to the classroom assistant or the instructors.

WOU's system also allows its tutors to grade TMAs and submit the grades for moderation. The instructors (lecturers) at the main campus would then selectively moderate the answer scripts of students. Feedback is then provided to the tutors on issues concerning the grades and perhaps the correct way to grade assignments. This becomes a learning process for the tutors that will help them perform better in the next round of grading. This also ensures the consistency of the marks given as students are spread all over the country. Both written feedback and verbal feedback are provided by the tutors as the system allows for it.

In contrast to Keller' plan, WOU tutors are not students who are currently enrolled in a programme in the university. They are either practitioners from the manufacturing industry or academic staff of other institutions who have demonstrated mastery of the subject matter in the form of relevant academic qualifications and work experience. Hence, apart from being subject matter experts, they may also bring with them extensive practical working experience that is essential when dealing with working adults. These amendments to the original PSI are vital to ensure that learning outcomes are met. 


\section{Conclusion}

Would Keller's PSI have worked in a distance learning environment? The answer is obvious. Nevertheless, it has to be customised based on the needs and requirements of the course or subject that it is used to deliver by taking into consideration students' expectations.

Further research is necessary as this pilot project was done mainly to see whether WOU is in line with the thinking of Fred Keller. All evidence shows that there are remnants of PSI in WOU. The manner in which it is administered is different as the needs of the students take precedence. There is also the issue of cultural differences between students in a Western setting as opposed to Asians.

Most studies or experiments are conducted in the Western world and little has been done to investigate the practices of Asian scholars. Perhaps there are other methods that are more suitable to us (Asians). Nevertheless, this experiment at WOU will continue until a more worthwhile conclusion can be derived.

Prakash Arumugam (email:prakashva@wou.edu.my) is with the School of Business Administration, Wawasan Open University, Penang, Malaysia.

\section{References}

Abbott, R. D., \& Falstrom, P. (1977). Frequent testing and Personalised systems of instruction. Contemporary Educational Psychology, 2, 251-257.

Belland, J. C., Taylor, W. D., Canelos, F., Dwyer, F., \& Baker, P. (1985). Is the self-paced instructional program, via microcomputer-based instruction, the most effective method of addressing individual learning differences? Educational Communication and Technology Journal, 33(3), 185-198.

Born, D. G., \& Herbert, E. W. (1974). A further study of Personalised instruction for students in large university classes. In J. M. Johnston (Ed.), Behaviour research and technology in higher education (pp. 125-127). Springfield: Charles C. Thomas.

Burnett, P. C. (2002). Teacher praise and feedback and students' perceptions of the classroom environment. Educational Psychology, 22(1). Retrieved from http://www.canterbury.ac.uk/ education/tf-mentors/TrainingYear/Stages/Progression/documents/TeacherPraise.pdf

Dubin, R., \& Taveggia, T. C. (1968). The teaching-learning paradox: A comparative analysis of college teaching methods. Eugene, OR: Center for the Advanced Study of Educational Administration. 
Fox, E. J. (2004). The Personalized System of Instruction: A flexible and effective approach to mastery learning. In D. J. Moran \& R. W. Malott (Eds.), Evidence-based educational methods (pp. $201-221$ ). San Diego: Elsevier Academic Press.

Gallup, H. F., \& Allan, R. W. (2002). Concerns with some recent criticisms of the Personalised System of Instruction (PSI). Lafayette College website. Retrieved from: http://ww2.lafayette. edu/\%7Eallanr/concerns.html

Grant, L. K., \& Spencer, R. E. (2003). The Personalised System of Instruction: Review and applications to distance education. International Review of Research in Open and Distance Learning, 4, 2.

Keller, F. S. (1968). “Good-bye, teacher ...”. Journal of Applied Behaviour Analysis, 1, 79-89.

Sherman, J. G. (1977). Individualizing instruction is not enough. Educational Technology, $17,56-60$.

Sherman, J. G. (1992). Reflections on PSI: Good news and bad. Journal of Applied Behaviour Analysis, 25, 59-64.

Taveggia, T. C. (1976). Personalised instruction: A summary of comparative research, 1967 -1974. American Journal of Physics, 44, 1028-1033.

Wang, A. Y., \& Newlin, M. H. (2000). Characteristics of students who enrol and succeed in psychology web-based classes. Journal of Educational Psychology, 92(1), 137-143.

Williams, K. C., \& Williams, C. C. (2011). Five key ingredients for improving student motivation. Research in Higher Education Journal, 12, 1 -23. Retrieved from http://www. aabri.com/manuscripts/11834.pdf

Wittig, S. (1974). Peer proctoring as a factor in motivation in self-paced composition courses: $O r$, how to help'em wanna better. Washington, DC: Center for Personalized Instruction. 